\title{
What Makes for a Pleasant Social Interaction? Motivational Dynamics of Interpersonal Relations
}

\author{
MICHELLE DOWNIE \\ McGill University \\ GENEVIEVE A. MAGEAU \\ University of Montréal \\ RICHARD KOESTNER \\ McGill University
}

\begin{abstract}
The authors used an event-contingent daily recording strategy, the Rochester Interaction Record (RIR), to examine the motivational dynamics of interpersonal relations. Using hierarchical linear modeling, the authors demonstrated that social interactions were more pleasant when participants felt autonomous, competent, and related. Autonomy, competence, and relatedness consistently predicted interaction quality, regardless of (a) the length of the interaction; (b) whether it was dyadic or in a group; and (c) whether it was an interaction with family, friends, or acquaintances. However, participants were more likely to report feeling autonomous and related when they were interacting either with family members and friends or in a dyadic situation. These results suggest that experiences of autonomy, competence, and relatedness may make a good day partly because they produce satisfying interpersonal experiences.
\end{abstract}

Keywords: autonomy, competence, relatedness, social interactions

THE QUESTION “HOW ARE YOU?” is often carelessly posed and just as thoughtlessly answered at multiple times throughout a person's day. Yet researchers continue to wrestle with this deceptively simple question. Researchers have attributed differences in subjective well-being, or happiness, to stable traits such as agreeableness and extraversion (DeNeve \& Cooper, 1998), optimism (Scheier \& Carver, 1993), self-esteem (Rosenberg, 1965), and a self-enhancing attributional style (Lyubomirsky \& Tucker, 1998).

This study was funded by grants to Richard Koestner from the Social Science and Humanities Research Council of Canada (SSHRC) and the Fonds pour la Formation de Chercheurs et l'Aide a la Recherche, Quebec (FCAR).

Address correspondence to Michelle Downie, School of Psychology, University of Ottawa, 145 Jean-Jacques Lussier, Lamoureux Room 352, Ottawa, ON, Canada, K1N 6N5; mdownie@uottawa.ca (e-mail). 
Although individual difference research has contributed much to the understanding of why one individual is happier than another, for laypeople these stable traits may not be particularly salient when they consider the question "How are you?" Kahneman (1997) argued that at any particular moment, people are likely to assess their well-being by comparing their recent past with their present circumstances. Thus, when most people reflect on their well-being, dispositional happiness may not be as accessible as day-to-day fluctuations in happiness. In determining what leads to these daily variations in well-being, researchers have relied on diary studies (e.g., Reis \& Wheeler, 1991). Frequently, researchers in diary studies ask participants to specifically report on their daily social interactions. Based on the results of such studies, researchers have reliably demonstrated that psychological well-being is positively related to the quantity and quality of a person's relationships (Nezlek, Richardson, Green, \& Schatten-Jones, 2002). In the present study, we consider the question "What makes for a good social interaction?" by building on previous research that has addressed the question "what makes for a good day?"

\section{Satisfaction of Needs and Well-Being}

Self-determination theory (SDT) is an empirically based theory of human motivation. Researchers of this theory have identified needs that they consider essential for optimal psychological development and functioning. They are classified as needs to further reflect the fact that the absence or thwarting of any one of them is highly harmful to an individual. The needs are autonomy, competence, and relatedness (Deci \& Ryan, 2000). Deci and Ryan state that competence is experienced when individuals perceive that they can affect change and influence the outcome of events, and relatedness is experienced when individuals feel close and connected to significant others. Researchers from other theoretical perspectives agree with the advocates of SDT's claims of the universality of the needs for competence (Bandura, 1997) and relatedness (Baumeister \& Leary, 1995). However, the assertion by SDT advocates that autonomy is also universally required has been more controversial.

In SDT, autonomy refers to volition or the individuals' perception that their behavior truly reflects their abiding interests, values, and sensibilities (Deci \& Ryan, 2000). Research conducted in domains ranging from political engagement (Koestner, Losier, Vallerand, \& Carducci, 1996) to recycling (Pelletier, 2002) to sports participation (Gagne, Ryan, \& Bargmann, 2003) has supported SDT advocates' assertion that autonomous engagement is associated with enhanced persistence and well-being in those particular domains. Once Ryan and Deci (2000) established that trait- and domain-specific levels of autonomy, competence, and relatedness were significantly associated with well-being, it was important for researchers to consider whether daily fluctuations in these three needs would have a similar impact on daily well-being. Using the diary-study methodology, previous researchers have found that negative events such as daily hassles (Rowlison \& Felner, 1988) and stressors (Mroczek \& Almeida, 2004) have a negative 
impact on well-being. Subsequently, SDT researchers reasoned that the positive experience of satisfying the basic needs should positively affect well-being. Sheldon, Ryan, and Reis (1996) tested this hypothesis in a daily diary study. The study involved asking participants to rate the three things on which they spent the most time during each day for 2 weeks on the dimensions of autonomy and competence. The results indicated that trait competence and autonomy were associated with higher well-being on average. Furthermore, daily fluctuations in competence and autonomy corresponded with changes in daily well-being, even after the researchers controlled for trait competence and autonomy.

A later study extended these results by including the need for relatedness (Reis, Sheldon, Gable, Roscoe, \& Ryan, 2000). Again using a daily diary methodology, participants rated the three activities that they spent the most time engaging in throughout their day on scales of autonomy, competence, and relatedness. Results supported the researchers' SDT-based hypotheses: Daily well-being was significantly related to daily experiences of autonomy, competence, and relatedness.

In the present study, we extended these findings by examining individuals' daily social interactions. We hypothesized that the same three needs associated with trait well-being and daily well-being would also be associated with wellbeing during social interactions. That is, interactions in which an individual reports feeling autonomous, competent, and related were expected to be associated with higher well-being. For the purposes of a daily social interaction study, we conceptualized well-being as an interaction quality (Reis \& Wheeler, 1991) to allow the greater temporal comparisons and variation that are necessary when assessing well-being across an individual's daily social interactions.

\section{Characteristics of the Interaction That Promote Quality and Need Satisfaction}

We thought that two characteristics of an interaction-(a) the relationship that one has with the person with whom one is interacting and (b) whether the interaction is dyadic or involving a group of people-may influence ratings of interaction quality, autonomy, competence, and relatedness. Close personal relationships serve an important function because they provide an individual with a sense of safety and security. They can relieve distress and anxiety in times of need (Collins \& Feeney, 2000). Close relationships can also act as a secure base from which one can reach out and explore one's environment (Green \& Campbell, 2000). In the context of social interactions, previous researchers have shown that highly intimacy-oriented individuals tend to determine their levels of self-disclosure on the basis of the closeness of their relationships with their interaction partners (Craig, Koestner, \& Zuroff, 1994). That is, intimacymotivated individuals show an adaptive pattern of self-disclosure in which they reveal more to others who are close to them than to acquaintances or strangers. It is interesting that another study showed that autonomy was associated with the same adaptive pattern of matching levels of self-disclosure to relationship 
closeness (Hodgins, Koestner, \& Duncan, 1996). When considering the impact of having either a dyadic or group interaction, researchers have indicated that highly intimacy-motivated individuals spend more time in dyadic interactions than in group interactions and that they tend to experience higher levels of subjective well-being (McAdams, Healy, \& Krause, 1984). The results of these studies point to the importance of distinguishing interactions on the basis of (a) the level of closeness to partners and (b) whether the interactions are dyadic or group interactions.

\section{Present Study}

The purpose of the present study was to determine the effects of need satisfaction on the quality of individuals' social interactions. We used the Rochester Interaction Record (RIR), an event-contingent daily recording strategy, to examine the relation of autonomy, competence, and relatedness to the overall quality of an interaction. We measured autonomy in terms of authenticity (i.e., "I felt I was myself") and assessed relatedness in terms of felt intimacy and reports of disclosure. We directly assessed competence by asking the participants to indicate how competent they felt during the interaction. We hypothesized that when these three needs were met, individuals would report greater quality in that particular social interaction. We also anticipated that (a) the relationship that one has with one's interaction partner and (b) the type of interaction that one is having (i.e., dyadic or group) would influence quality ratings and ratings of autonomy, competence, and relatedness. Subsequently, we expected that interactions with family and friends would be rated higher in terms of quality, autonomy, and relatedness, whereas dyadic interactions would be rated higher in terms of autonomy and relatedness.

\section{Method}

\section{Participants}

Participants were 112 individuals -39 were men and 73 were women ( $M$ age $=20.2$ years, $S D=2.9$ years). In all, 22 participants failed to complete the interaction record. Participants who opted not to finish the study did not differ in terms of age or gender from the participants who did complete the study.

\section{Procedure}

We recruited participants from a paid participant pool at McGill University. Respondents were paid \$30. Participants came into the lab to receive detailed instructions on how to fill out the RIRs (Wheeler \& Nezlek, 1977). For 1 week after the initial lab session, participants completed one record for every social 
interaction that they had that lasted 10 min or longer. Thus, each participant completed a unique number of interaction records that depended on how many conversations he or she had over the course of 1 week. On average, participants completed 35.2 reports $(S D=19.67$ reports) regarding their social interactions at discrete points in time throughout the week. The number of interactions, ranging from 5 to 111, varied widely by participant. On average, the interactions lasted $55 \mathrm{~min}(S D=1 \mathrm{hr} 12 \mathrm{~min})$. At the end of the week, participants returned the completed records, and then we gave them the opportunity to ask us questions, a debriefing sheet that provided them with more information on the study, and an e-mail address to use to contact us if any further questions arose or if they wished to know the results of the study.

\section{Research Materials}

$R I R$. The interaction record was event-contingent in that the participants would complete one record for every social interaction they had that lasted $10 \mathrm{~min}$ or more. Interactions could occur in person, over the phone, or via the Internet (i.e., chatting online; e-mailing did not qualify because it is not interactive). We asked participants to complete each record as soon as possible after each interaction. We used a slightly modified version of the RIR (Wheeler \& Nezlek, 1977) to assess social interactions. Each record included the date, time, length of the interaction, and relationship to the interaction partner (e.g., friend, sibling). In addition, participants were also asked to rate each interaction on the dimensions of autonomy, competence, relatedness, and quality.

Autonomy. In the context of a social interaction, people feel autonomous when they are acting in a manner that is consistent with their sense of self (i.e., they are experiencing themselves as behaving in a volitional manner so that they fully endorse and stand behind their behavior). In other words, people feel autonomous when they are being authentic. Previous SDT researchers have measured authenticity in part by asking participants to rate the statement "I experience this aspect of myself as an authentic part of who I am" (Sheldon, Ryan, Rawsthorne, \& Ilardi, 1997). In the present study, we asked participants to rate how they felt during an interaction on the basis of the dimension of authenticity by rating the interaction on a continuous Likert-type scale ranging from 1 (I wasn't myself) to 7 (I was myself).

Competence. Competence pertains to the extent to which people feel efficacious during an interaction. Reis et al. (2000) assessed competence by asking participants how effective they felt while performing an activity. In the context of social interactions, we asked participants to indicate how they felt in the interaction on a Likert-type scale ranging from 1 (very little competence) to 7 (a great deal of competence). 
Relatedness. In assessing the relatedness of an interaction, we followed the example of previous researchers (Parks \& Floyd, 1996; Reis et al., 2000; Reis \& Patrick, 1996) in conceptualizing relatedness as those interactions in which the actors discussed personally relevant matters. We calculated the relatedness score as an average of three items: the participants' rating of intimacy on a Likert-type scale ranging from 1 (superficial) to 7 (meaningful) and two separate ratings of how much the participant disclosed to the partner and how much the partner disclosed to the participant. Participants rated the disclosure by "I" or "other" on a continuous scale ranging from 1 (very little) to 7 (a great deal). Cronbach's alpha for these items was .80 .

Quality. We assessed interaction quality by asking participants to rate the interaction on a Likert-type scale ranging from 1 (unpleasant) to 7 (very pleasant). In assessing this rating, we followed the exact procedure for assessing quality in the RIR (Reis \& Wheeler, 1991).

\section{Results}

\section{Overview of Analyses}

The interaction data were a hierarchically structured data set in which repeated interaction measures (Level 1) were nested in participants (Level 2). Thus, we chose hierarchical linear modeling (HLM) with the restricted maximum likelihood method of estimation (Raudenbush \& Bryk, 2002) as the most appropriate statistical analytic procedure for this type of data set (Nezlek, 2003). HLM can tolerate missing data and uneven case numbers within participants, both of which are common in diary studies.

We first considered - at a within-person level-the influences of autonomy, competence, and relatedness on the quality of an interaction. We then considered the types of interactions that are associated with increased quality, autonomy, competence, and relatedness.

Table 1 shows the means and standard deviations for all Level 1 variables across all participants and interactions.

TABLE 1. Means and Standard Deviations for All Level 1 Variables

\begin{tabular}{lccc}
\hline \hline Variable & $n$ & $M$ & $S D$ \\
\hline Autonomy & 3,188 & 5.96 & 1.21 \\
Competence & 3,152 & 5.42 & 1.31 \\
Relatedness & 3,187 & 4.57 & 1.42 \\
Quality & 3,179 & 5.70 & 1.19
\end{tabular}




\section{Predictors of Interaction Quality}

In a first step, we tested the unconditional models for the dependent variable of quality to determine how the between-persons variance and the within-person variance were partitioned. Intraclass correlations were calculated from the withinperson and between-persons variances of the unconditional models (Raudenbush $\&$ Bryk, 2002). Results showed that for interaction quality, there was more variability between interactions than between participants (within-person variance $=$ $82.34 \%$, between-person variance $=17.66 \%$ ).

Our first hypothesis was that autonomy, competence, and relatedness would be associated with interaction quality. Results of this analysis are in Table 2. The grand mean for quality was $5.70\left(\gamma_{00}\right)$. Interactions in which participants felt autonomous $\left(\gamma_{10}=.19, p<.001\right)$, competent $\left(\gamma_{10}=.26, p<.001\right)$, and related $\left(\gamma_{10}=\right.$ $.17, p<.001)$ corresponded with interactions that participants rated as more pleasant. Including autonomy, competence, and relatedness as predictors of interaction quality allowed us to account for $35.62 \%$ of the variance in participants' ratings of interaction quality. These findings remained significant when we controlled for interaction length, the nature of one's interaction partner (i.e., family and friends vs. employers, coworkers, and acquaintances), and the type of interaction (i.e., dyadic vs. group). Thus — as expected on the basis of SDT - when the three needs for autonomy, competence, and relatedness were met, participants reported enhanced well-being, or quality, from an interaction.

\section{Characteristics Promoting Quality, Autonomy, Competence, and Relatedness}

We thought it important to consider whether (a) the relationship that one has with one's interaction partner or (b) the type of interaction (i.e., dyadic or group) would foster greater interaction quality, autonomy, competence, and relatedness.

TABLE 2. Conditional Model for Quality with Autonomy, Competence, and Relatedness as Level 1 Predictors

\begin{tabular}{lcc}
\hline \hline Fixed effect & Quality coefficient & $p$ \\
\hline $\begin{array}{l}\text { Means as outcomes } \beta_{0 \mathrm{j}} \\
\text { Intercept }\left(\gamma_{00}\right)\end{array}$ & 5.70 & .001 \\
Slopes as outcomes $\beta_{\mathrm{ij}}$ & & \\
Autonomy $\left(\gamma_{10}\right)$ & .19 & .001 \\
Competence $\left(\gamma_{20}\right)$ & .26 & .001 \\
Relatedness $\left(\gamma_{30}\right)$ & .17 & .001 \\
\hline
\end{tabular}

Note. Level 1 Equation is Quality ${ }_{\mathrm{ij}}=\beta_{0 \mathrm{j}}+\beta_{1 \mathrm{j}}$ (autonomy) $+\beta_{2 \mathrm{j}}$ (competence) $+\beta_{3 \mathrm{j}}$ (relatedness) $+\mathrm{r}_{\mathrm{ij}}$. 
We dummy coded all interactions as either 0 (with family and friends) or 1 (with employers, coworkers, and acquaintances). For clarity, interactions that involved a mixture of family, friends, and coworkers were excluded from the present analyses. We considered this reasonable because such interactions only accounted for $6.4 \%$ of the total interactions. In addition, participants indicated whether each interaction was either dyadic (coded as 0 ) or with a group (coded as 1).

Participants rated interactions with family and friends as more pleasant than those with coworkers, employers, and acquaintances $\left(\gamma_{10}=-.60, p<.001\right.$; grand $M$ for quality $\left.\left[\gamma_{00}\right]=5.80\right)$. However, quality ratings did not differ with whether the interaction was dyadic or with a group $\left(\gamma_{10}=-.03, p=.62\right)$. Similarly, participants indicated feeling more competent in interactions with family and friends $\left(\gamma_{10}=-.59, p<.001\right.$; grand $M$ for competence $\left.\left[\gamma_{00}\right]=5.48\right)$. Competence was also independent of the type of interaction $\left(\gamma_{10}=-.09, p=.16\right)$. Participants indicated feeling most autonomous and related in interactions with family and friends $\left(\gamma_{10 a u t o n o m y}=-1.01, p<.001\right.$; grand $M$ for autonomy $\left[\gamma_{00}\right]=6.19$; $\gamma_{10 \text { relatedness }}=-1.16, p<.001$; grand $M$ for relatedness $\left.\left[\gamma_{00}\right]=4.87\right)$ and during dyadic interactions $\left(\gamma_{10 \text { autonomy }}=-.28, p<.001 ; \gamma_{10 \text { relatedness }}=-.41, p<.001\right)$. It was not surprising that taken together the results indicated (a) participants rated interactions with family members and friends as opposed to those with coworkers, employers, and acquaintances as more pleasant and (b) participants indicated that they felt more autonomous, competent, and related in those interactions. In addition, participants were more likely to report feeling autonomous and related in dyadic interactions.

\section{Discussion}

In this study, our purpose was to extend the research by Reis et al. (2000) by examining the effects of autonomy, competence, and relatedness in one's daily social interactions. Satisfaction of these three needs had previously been associated with daily fluctuations in well-being. Our results indicated that interactions in which participants felt autonomous, competent, and related were rated as more pleasant. Moreover, autonomy, competence, and relatedness were still significant predictors of interaction quality even when we took the relationship with the interaction partner and the type of interaction into account. However, the relationship that participants had with their interaction partner did influence interaction quality, competence, autonomy, and relatedness.

In line with our hypotheses, participants rated their interactions as more pleasant, autonomous, and related when they occurred with family and friends as opposed to when participants interacted with coworkers and acquaintances. In addition, participants indicated feeling more competent in interactions with family members and friends. Although we had not specifically hypothesized the latter outcome, perhaps in the more secure relationships with family and friends, individuals felt freer to express their views, and that feeling may have translated 
into feeling more efficacious about what they were communicating. Thus, in the present study, close relationships were more likely to fulfill the needs for autonomy, relatedness, and competence. Future researchers should consider how the development of a close relationship and need satisfaction are related to each other. That is, does a relationship become close because it has the capacity to satisfy individuals' needs from the beginning? Or does the capacity to satisfy needs only come after a relationship has become close?

Interaction type also had a significant effect on need satisfaction. As expected, participants reported feeling more autonomous and more related during dyadic interactions. These results confirmed our hypothesis that one-on-one interactions would facilitate authentic self-expression and provide more of an opportunity for individuals to disclose personally meaningful things about themselves and for their partners to reciprocate this disclosure. Quality and competence were unaffected by interaction type. As anticipated, it appears that dyadic and group interactions were equally pleasant and that participants felt equally capable in each type of interaction. Thus, in support of previous research (McAdams et al., 1984), it appears that individuals seek dyadic interactions when they expressly want to feel greater autonomy or relatedness.

It is interesting to note that in the present study, we asked participants to report on all interactions that lasted $10 \mathrm{~min}$ or more. Thus, it is conceivable that in a mere $10 \mathrm{~min}$ an individual could have an interaction that would satisfy all of the three needs and thus be associated with higher well-being. Alternatively, in those same $10 \mathrm{~min}$, all three needs could be thwarted, and the individual's wellbeing could plummet. Previous researchers have found the thwarting of need to be associated with incongruent behavior (Sheldon et al., 1997) and amotivation (Boggiano, 1998). Moreover, the individual who maintains these thwarting types of relationships over the long term will likely adapt by developing compensatory motives that, although not conducive to optimal development, confer some shortterm advantages in these adverse situations (Deci \& Ryan, 2000). For example, teens with mothers whose parenting style thwarted their needs were more likely to develop extrinsic aspirations (e.g., fame, wealth; Kasser, Ryan, Zax, \& Sameroff, 1995). These compensatory aspirations may seem adaptive to individuals whose basic needs have been thwarted as they will enable them to more overtly demonstrate their "value." However, this is cause for concern because subsequent researchers have demonstrated that extrinsic aspirations are not conducive to psychological well-being (Kasser \& Ryan, 1996). Future researchers should consider whether reactivity toward need thwarting depends on the person who is the cause. That is, if interactions with family and friends are more likely to cultivate an individual's feelings of autonomy, competence, and relatedness, then perhaps they are also more likely to incur compensatory need satisfaction when the individual is frustrated. In contrast, interactions with coworkers, although potentially frequent, may not have such detrimental effects because there is less of an expectation that these interactions should foster need satisfaction to as great 
an extent. Thus, the detrimental effects of failing to satisfy one's needs may be compounded by the source of that frustration.

Future researchers should also consider the impact of need-satisfying interactions on an individual's daily well-being. We anticipate that a day in which the majority of a person's social interactions satisfies that individual's needs for autonomy, competence, and relatedness would result in increased daily wellbeing. Of course, it remains to be seen whether those three needs could be satisfied independently over the course of multiple interactions with the same beneficial effects. That is, if individuals are able to meet their needs for competence by interacting with colleagues, for autonomy by participating in recreational activities, and for relatedness by interacting with their partner, would the individuals have the same daily well-being as other individuals who satisfy all three needs simultaneously? We anticipate that the individual whose needs are met separately will have slightly lower well-being in each interaction. But as long as the other two needs are only being neglected and are not actually thwarted in each type of interaction, then that individual may still have the same overall high levels of daily well-being. In other words, it may be possible to store need-satisfying experiences and reap the benefits at the end of the day.

Researchers should note some limitations when drawing conclusions from this study. Although the daily diary methodology that we used does have many advantages (e.g., avoiding recall biases), it is still correlational in nature and does not allow researchers to infer causality. Therefore, researchers may be concerned that the results of the present study reflect a halo effect. That is, in the present study, more pleasant interactions may have been considered higher in need satisfaction post hoc. However, the very nature of the diary study may have helped to protect against this possibility. In particular, the specificity of the items that we asked participants to rate and the fact that we designed each record to take approximately $30 \mathrm{~s}$ should have reduced participants' tendencies to overanalyze their social interactions.

In conclusion, the results of the present study serve to further confirm SDT advocates' claims of the importance of autonomy, competence, and relatedness to an individual's well-being. Our findings indicated that regardless of the type of interaction (dyadic vs. group) and the type of partners (family and friends vs. acquaintances), the individual was more likely to indicate that he or she had a pleasurable experience if these three needs were met. Thus, the answer to the question "What makes a good conversation?" seems to be "The felt experiences of autonomy, competence, and relatedness."

\section{AUTHOR NOTES}

Michelle Downie is a postdoctoral fellow at the University of Ottawa. Her research examines the influence of cultural internalization and cultural values on well-being. Genevieve Mageau is a psychology professor at the University of Montreal. Her current research focuses on the determinants and outcomes of autonomy support in hierarchical 
relationships in general and in parent-child interactions in particular. Richard Koestner is a psychology professor at McGill University. He conducts research on goal setting, self-regulation, and internalization processes.

\section{REFERENCES}

Bandura, A. (1997). Self-efficacy: The exercise of control. New York: W. H. Freeman/ Times Books/Henry Holt \& Co.

Baumeister, R., \& Leary, M. R. (1995). The need to belong: Desire for interpersonal attachments as a fundamental human motivation. Psychological Bulletin, 117, 497-529.

Boggiano, A. K. (1998). Maladaptive achievement patterns: A test of a diathesis-stress analysis of helplessness. Journal of Personality and Social Psychology, 74, 1681-1695.

Collins, N. L., \& Feeney, B. (2000). A safe haven: An attachment theory perspective on support seeking and care giving in close relationships. Journal of Personality and Social Psychology, 78, 1053-1073.

Craig, J-A., Koestner, R., \& Zuroff, D. C. (1994). Implicit and self-attributed intimacy motivation. Journal of Social and Personal Relationships, 11, 491-507.

Deci, E. L. \& Ryan, R. M. (2000). The "what" and "why" of goal pursuits: Human needs and the self-determination of behavior. Psychological Inquiry, 11, 227-268.

DeNeve, K. M., \& Cooper, H. (1998). The happy personality: A meta-analysis of 137 personality traits and subjective well-being. Psychological Bulletin, 124, 197-229.

Gagne, M., Ryan, R. M., \& Bargmann, K. (2003). Autonomy support and need satisfaction in the motivation and well-being of gymnasts. Journal of Applied Sport Psychology, 15, 372-390.

Green, J. D., \& Campbell, W. K. (2000). Attachment and exploration in adults: Chronic and contextual accessibility. Personality and Social Psychology Bulletin, 26, 452-461.

Hodgins, H. S., Koestner, R., \& Duncan, N. (1996). On the compatibility of autonomy and relatedness. Personality and Social Psychology Bulletin, 22, 227-237.

Kahneman, D. (1997, May). The cognition of well-being. Keynote address presented at the meeting of the American Psychological Society, Washington, DC.

Kasser, T., \& Ryan, R. M. (1996). Further examining the American dream: Differential correlates of intrinsic and extrinsic goals. Personality \& Social Psychology Bulletin, 22, 280-287.

Kasser, T., Ryan, R. M., Zax, M., \& Sameroff, A. J. (1995). The relations of maternal and social environments to late adolescents' materialistic and prosocial values. Developmental Psychology, 31, 907-914.

Koestner, R., Losier, G. F., Vallerand, R. J., \& Carducci, D. (1996). Identified and introjected forms of political internalization: Extending self-determination theory. Journal of Personality \& Social Psychology, 70, 1025-1036.

Lyubomirsky S., \& Tucker, K. L. (1998). Implications of individual differences in subjective happiness for perceiving, interpreting and thinking about life events. Motivation \& Emotion, 22, 155-186.

McAdams, D. P., Healy, S., \& Krause, S. (1984). Social motives and patterns of friendship. Journal of Personality and Social Psychology, 47, 828-838.

Mroczek, D. K., \& Almeida, D. M. (2004). The effect of daily stress, personality, and age on daily negative affect. Journal of Personality, 72, 355-378.

Nezlek, J. B. (2003). Using multilevel random coefficient modeling to analyze social interaction diary data. Journal of Social \& Personal Relationships, 20, 437-469.

Nezlek, J. B., Richardson, D. S., Green, L. R., \& Schatten-Jones, E. C. (2002). Psychological well-being and day-to-day social interaction among older adults. Personal Relationships, 9, 57-71. 
Parks, M. R., \& Floyd, K. (1996). Meanings for closeness and intimacy in friendship. Journal of Social \& Personal Relationships, 13, 85-108.

Pelletier, L. G. (2002). A motivational analysis of self-determination for pro-environmental behaviors. In E. L. Deci \& R. M. Ryan (Eds.), Handbook of self-determination research (pp. 205-232). Rochester, NY: University of Rochester Press.

Raudenbush, S. W., \& Bryk, A. S. (2002). Hierarchical linear models: Applications and data analysis methods (2nd ed.). Thousand Oaks, CA: Sage.

Reis, H. T., \& Patrick, B. C. (1996). Attachment and intimacy: Component processes. In E. T. Higgins \& A. W. Kruglanski (Eds.), Social psychology: Handbook of basic principles (pp. 523-563). New York: Guilford Press.

Reis, H. T., Sheldon, K. M., Gable, S. L., Roscoe, J., \& Ryan, R. M. (2000). Daily wellbeing: The role of autonomy, competence, and relatedness. Personality \& Social Psychology Bulletin, 26, 419-435.

Reis, H. T., \& Wheeler, L. (1991). Studying social interaction with the Rochester Interaction Record. In M. P. Zanna (Ed.), Advances in experimental social psychology (Vol. 24, pp. 270-318). San Diego, CA: Academic Press.

Rosenberg, M. (1965). Society and the adolescent self-image. Princeton, NJ: Princeton University Press.

Rowlison, R. T., \& Felner, R. D. (1988). Major life events, hassles, and adaptation in adolescence: Confounding in the conceptualization and measurement of life stress and adjustment revisited. Journal of Personality \& Social Psychology, 55, 432-444.

Ryan, R. M., \& Deci, E. L. (2000). Self-determination theory and the facilitation of intrinsic motivation, social development, and well-being. American Psychologist, 55, 68-78.

Scheier, M. F., \& Carver, C. S. (1993). On the power of positive thinking: The benefits of being optimistic. Current Directions in Psychological Science, 2, 26-30.

Sheldon, K. M., Ryan, R. M., Rawsthorne, L. J., \& Ilardi, B. (1997). Trait self and true self: Cross-role variation in the Big-Five personality traits and its relations with psychological authenticity and subjective well-being. Journal of Personality \& Social Psychology, 73, 1380-1393.

Sheldon, K. M., Ryan, R., \& Reis, H. T. (1996). What makes for a good day? Competence and autonomy in the day and in the person. Personality \& Social Psychology Bulletin, 22, 1270-1279.

Wheeler, L., \& Nezlek, J. (1977). Sex differences in social participation. Journal of Personality and Social Psychology, 54, 323-333.

Received February 5, 2007

Accepted July 9, 2007 